\title{
Viewing Pharmacy through a Public Health Lens
}

\author{
Neil J MacKinnon
}

Since 1989, a significant portion of my life has been Sinterconnected with the profession of pharmacy. From completing my undergraduate and graduate education in pharmacy, then working as a hospital pharmacist and community pharmacist and as a faculty member at a college of pharmacy, to serving with pharmacy organizations such as CSHP: even my nonpharmacist friends knew that pharmacy was a large part of my identity.

That all changed to some degree last summer when our family moved to Tucson, Arizona, and I became a Professor of Public Health at the University of Arizona and Director of its Center for Rural Health (www.crh.arizona.edu/). Yes, I am as much a pharmacist today as I was a year ago, but for the first time in over 23 years, I am not surrounded by pharmacists and pharmacy educators, and most of my activities are not related to pharmacy issues. I am teaching a graduate-level course on rural health policy this semester. Our Center houses the State Office of Rural Health, and through that office I am working on a variety of rural health issues, including emergency medical services, patient safety and quality improvement in rural hospitals, American Indian health, and community health assessments. It has been a fascinating experience to date, and, as a pharmacist, I feel that I can offer a unique perspective on these issues and make a real contribution.

In some ways, it has been an out-of-body experience to view our profession from an outside perspective. At the same time, I am more convinced than ever of the value that pharmacists provide to individual patients and to society as a whole.

From a public health perspective, there is much to which pharmacists can contribute, from vaccination programs to disease management and prevention to health education. CSHP recognizes this as 1 of the 6 goals of CSHP 2015: "Increase the extent to which pharmacy departments in hospitals and related healthcare settings engage in public health initiatives on behalf of their communities" (www.cshp.ca/programs/cshp2015/ index_e.asp).
Here in the United States, the Office of the Chief Pharmacist recently released a pertinent report to the US Surgeon General. ${ }^{1}$ This report discusses the valuable role that pharmacists play, noting that "pharmacists are remarkably underutilized in the U.S. health care delivery system given their level of

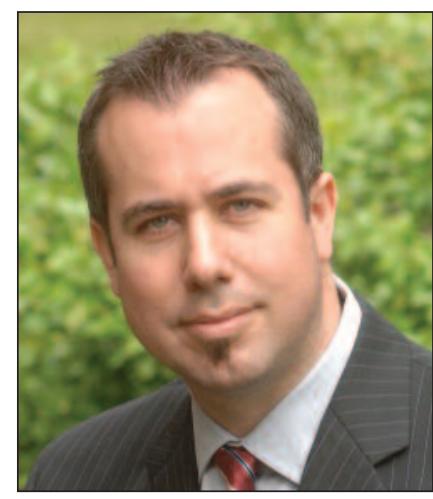
education, training, and access to the community." Moreover, the report lists as one of its primary 4 objectives to "advance beyond discussion (and numerous demonstration projects) of the expanded roles of pharmacist-delivered patient care and move toward health system implementation."

So, let's all do our part to ensure our skills are properly utilized and implemented ... for individual patients and for the health of the public.

\section{Reference}

1. Giberson S, Yoder S, Lee MP. Improving patient and health system outcomes through advanced pharmacy practice. A report to the U.S. Surgeon General 2011. US Public Health Service, Office of the Chief Pharmacist; 2011 Dec [cited 23 May 2012]. Available from: www.usphs.gov/corpslinks/pharmacy/ documents/2011 AdvancedPharmacyPracticeReporttotheUSSG.pdf

Neil J MacKinnon, BSc(Pharm), MSc(Pharm), PhD, FCSHP, is Past President and Vision Liaison of the CSHP. 